\title{
Collecting, discarding, and re-collecting of protein-rich food in a natural colony of Camponotus japonicus
}

\author{
Hangah Lim $^{1} \cdot$ Jibeom Choi $^{1} \cdot$ Woncheol Song ${ }^{1} \cdot$ Sang-im Lee ${ }^{1,2} \cdot$ Piotr G. Jablonski ${ }^{1,3}$
}

Received: 18 September 2018 / Accepted: 27 May 2019 / Published online: 28 June 2019

(c) The Author(s) 2019

\begin{abstract}
Ants are known for their collective intelligence and efficient division of labor. Therefore, observations that seem to contradict these stereotypes are worth reporting. While observing a colony of Camponotus japonicus, we discovered that workers frequently dumped protein-rich food items at a particular spot, while other workers collected the dumped food items and brought them back to the nest. These two counteractive processes were performed simultaneously by the same colony, which indicates possible inefficiency of their collective labor. Discarding a specific type of food to calibrate the nutritional balance of a colony has been previously reported, but we found no reports on re-collecting discarded food. We suspect that this phenomenon might have been an outcome of communication inefficiency within the colony, or that the putative dump site might have served as a temporary deposit of food items before they were redistributed inside the nest.
\end{abstract}

Keywords Collective intelligence $\cdot$ Collective labor $\cdot$ Carpenter ant $\cdot$ Communication

\section{Introduction}

Ants exhibit collective intelligence in breeding, foraging, and nest-building (Garnier et al. 2007; Hölldobler and Wilson 1990), and they selectively store a portion of gathered food in the nest (Reyes-López and Fernández-Haeger 2002). The availability of a large number of food items for storage may require a temporary cache to facilitate the efficient

Hangah Lim and Jibeom Choi contributed equally to this work.

Electronic supplementary material The online version of this article (https://doi.org/10.1007/s10164-019-00607-4) contains supplementary material, which is available to authorized users.

Sang-im Lee

sangim@dgist.ac.kr

$\triangle$ Piotr G. Jablonski

snulbee@behecolpiotrsangim.org

1 Laboratory of Behavioral Ecology and Evolution, School of Biological Sciences, Seoul National University, Seoul 08826, Republic of Korea

2 School of Undergraduate Studies, Daegu-Gyeongbuk Institute of Science and Technology (DGIST), Daegu 42988, Republic of Korea

3 Museum and Institute of Zoology, Polish Academy of Sciences, Warsaw 00-679, Poland redistribution of food within a nest. Meanwhile, the longevity of a colony is affected by the amount of protein consumed (Dussutour and Simpson 2012). Therefore, some ant species regulate the nutritional balance of the colony by controlling the protein content of the food stored in the nest and dumping excessive food outside of the nest in a collective manner (Cook and Behmer 2010; Dussutour and Simpson 2009).

Here we report observations of food dumping by Camponotus japonicus, which are unusual in that the dumped food was carried back to the nest. We found no previous reports on this behavior, i.e., re-collecting previously discarded food from an outside dump to bring it back to the nest. We give a description of this phenomenon here and discuss hypothetical explanations for it. Our hypotheses include discordance of food acceptance among the ants and the utilization of an external dump as a cache site.

\section{Materials and methods}

The phenomenon reported here was discovered by chance during a systematic series of experiments carried out at the Gwanak campus of Seoul National University $\left(37^{\circ} 27^{\prime} \mathrm{N}\right.$, $126^{\circ} 57^{\prime} \mathrm{E}$ ) in June-September 2017. These experiments involved observing ants on a $60-\mathrm{cm} \times 60-\mathrm{cm}$ arena made of white foam board placed near their nest. We used canned 

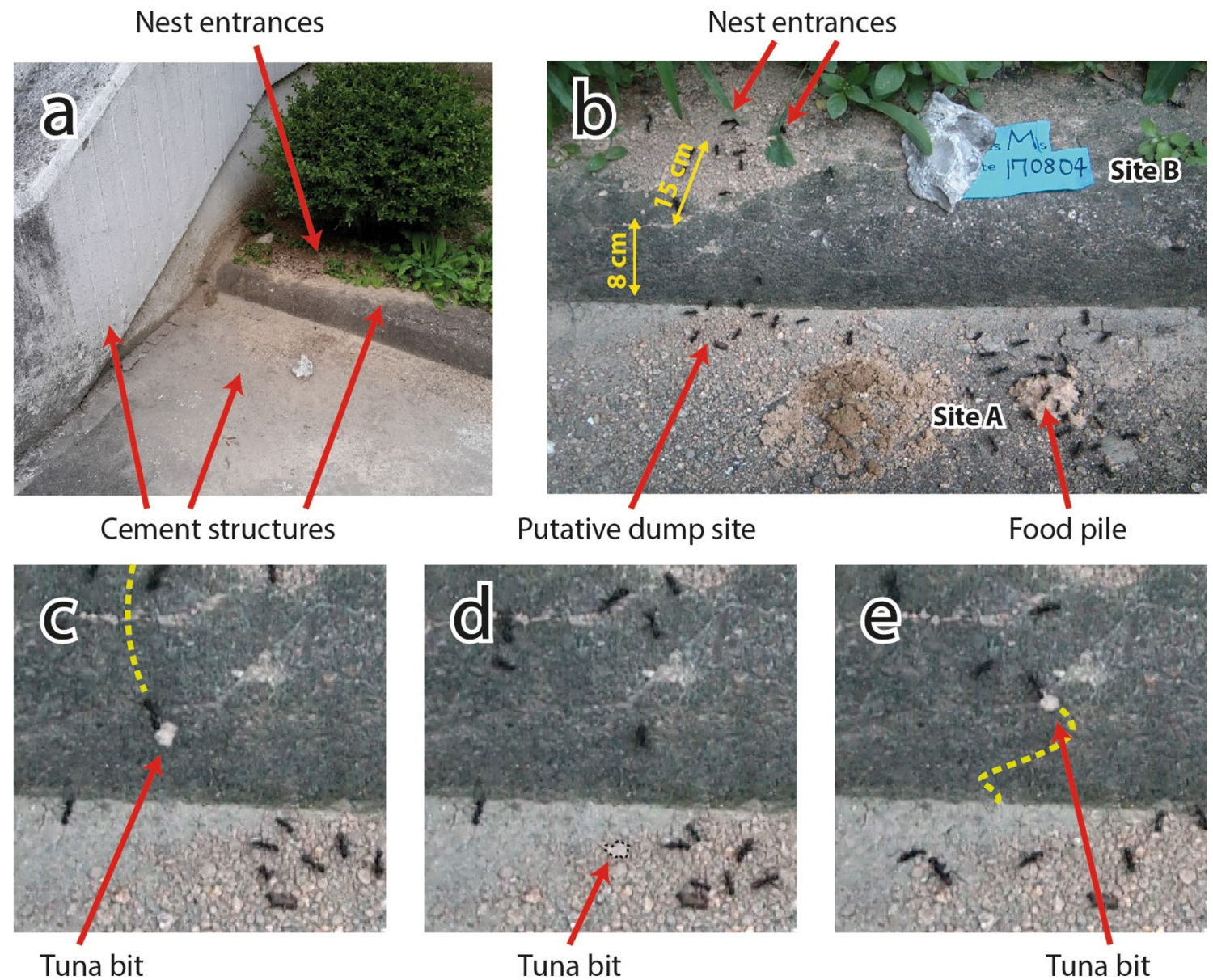

Fig. 1a-e Photographic documentation of the ant nest where the recollecting phenomenon was observed. a The nest was located near artificial structures: paving, the curb of a planter, and cement wall adjacent to a building. $\mathbf{b}$ The entrances to the nest were near the curb of the planter. The putative dump site was located on the ground where ants dropped bits of food from a higher level (the top of the curb). The food pile provided by us was located either on the curb (Site B) or on the paving (Site A). In both cases, the location of the putative dump site remained unchanged. The horizontal distance from the nest entrance to the dump site was $15 \mathrm{~cm}$, while the vertical difference in height was $8 \mathrm{~cm}$. c An ant carries a tuna bit out of the nest and drops it onto the putative dump site. Dashed lines indicate the trajectory of the food-carrying ant. $\mathbf{d}$ The tuna bit (highlighted by the dashed line) is left unattended until another worker comes to collect it (in this case, it took $36 \mathrm{~s}$ for the tuna bit to be dragged after it had been abandoned). e The tuna bit is collected and pulled back into the nest by a different worker than the one that abandoned it

decided to look more closely for this after each of the originally planned experimental trials. To this end, we videotaped this behavior on seven different occasions.

This dumping behavior was already occurring at the end of each of the original experiments, as was the bringing back of tuna bits from the dump to the nest. For each observation, we removed the experimental arena and placed fresh tuna mixed with sugar (about $18 \mathrm{~g}$ ) on the cement curb of a planter near the nest or near the putative dump site (Fig. 1) before filming the behavior. Each observation was conducted on a different day (Table 1); an annotated video clip is available online (Supplementary material). The colony in which the described phenomenon occurred was located in a relatively shadier location than the other two other colonies due 
Table 1 Brief description of seven video recordings of collecting-discarding-retrieving behavior

\begin{tabular}{llllll}
\hline $\begin{array}{l}\text { Observa- } \\
\text { tion ID }\end{array}$ & Filming date & $\begin{array}{l}\text { Start time } \\
\text { (hours) }\end{array}$ & End time (hours) & $\begin{array}{l}\text { Duration } \\
\text { (minimum) }\end{array}$ & $\begin{array}{l}\text { Average } \\
\text { temperature } \\
\left({ }^{\circ} \mathrm{C}\right)\end{array}$ \\
\hline 1 & 18 July 2017 & 1837 & 1950 & 73 & 26.5 \\
2 & 27 July 2017 & 1852 & 1933 & 41 & 27.1 \\
3 & 1 August 2017 & 1806 & 1941 & 95 & 28.6 \\
4 & 4 August 2017 & 1834 & 1959 & 75 & 30.3 \\
5 & 11 August 2017 & 1820 & 1932 & 72 & 27.0 \\
6 & 22 August 2017 & 1841 & 1922 & 41 & 27.3 \\
7 & 20 September 2017 & 1723 & 1838 & 75 & 19.5 \\
\hline
\end{tabular}

Out of 14 visits to the colony for the originally planned experiments, we confirmed eight incidences of this collecting-discarding-retrieving behavior and succeeded in making seven video recordings of it. We do not know whether this behavior occurred at other times. The filming started at around 6 p.m. in July and August, and 5 p.m. in September. The duration of each video recording exceeded $40 \mathrm{~min}$

${ }^{a}$ Data from the Korea Meteorological Administration (KMA) homepage (http://www.kma.or.kr) to adjacent structures. All colonies were $\leq 170 \mathrm{~m}$ from each other.

We analyzed 4 min of each video recording, starting at $1 \mathrm{~min}$ after the initiation of the movie. We counted the occurrence of three types of behaviors during this period: carrying tuna bits from the fresh tuna pile to the nest (CF), discarding tuna bits from the nest at the dump area (D), and carrying tuna bits from the dump back to the nest (CD). One occurrence represents one ant that carried tuna between two points out of the three locations (tuna pile, dump, nest entrance). In observations $1-4$, we placed the food pile on the cement floor near the dump site (Fig. 1b, Site A). In observations 5-7, we placed the food pile on the cement curb of the planter (Fig. 1b, Site B). We measured the intensity of each behavior separately as a number of incidences per 4-min video clip. One-way repeated measures ANOVA on ranks was used to test whether the intensities of these three types of behavior were statistically different. We generated a linear mixed-effects model based on ranks using the nlme package (Pinheiro et al. 2007), setting the observations (1-7) as random effects. Post-hoc analysis was conducted by Tukey's test using lsmeans package (Lenth 2016) for pairwise comparisons. We used the Wilcoxon signed-rank test to compare the intensity of the total food influx into the nest $(\mathrm{CF}+\mathrm{CD})$ and that of the food discarding (D). All statistical analyses were conducted using $\mathrm{R}$ version 3.5.1.

\section{Results}

The intensity of food discarding (D; Fig. 2) and bringing the discarded food from the dump (CD) did not differ ( $p=0.5271$; one-way repeated measures ANOVA on ranks followed by Tukey's test). However, the intensity of carrying fresh tuna bits to the nest $(\mathrm{CF})$ was lower than the intensity of discarding food (D; $p<0.01$, one-way repeated measures ANOVA on ranks followed by Tukey's test; Fig. 2b) and the intensity of bringing bits from the dump (CD; $p<0.05$, one-way repeated measures ANOVA on ranks followed by Tukey's test; Fig. 2b). The intensity of total influx of tuna bits into the colony $(\mathrm{CF}+\mathrm{CD})$ was not significantly different from that of food discarding (D) from the colony ( $p=0.5271$, Wilcoxon signed-rank test).

Most of the time, ants dumped the tuna bits on the flat area below the planter curb and occasionally dumped the food in the immediate vicinity of the nest entrance. We confirmed that some individuals frequently brought the food back to the nest later on. In some cases, the dumped tuna bits were picked up again by other workers and dumped at different sites. In one case, an ant discarded a tuna bit, and another ant immediately picked it up to carry it back to the nest. Some workers that had previously discarded their own food often found other bits nearby (presumably the bits dumped out of the nest earlier by other ants) and dumped them again. Some ants even snatched other ants' tuna bits and discarded them. Finally, we observed one case of an ant carrying food out of the nest and returning to the nest without discarding the tuna bit. There was no indication that the ants covered the food with other objects.

\section{Discussion}

We are not aware of any report describing behaviors similar to those that we observed in the present study. We suspect that this is the first observation of a natural colony performing two different behaviors that counteract each other: discarding food from the nest and, at the same time, collecting the food from the dump area. This phenomenon seems to be inefficient and redundant, as food items are dragged back and forth. If the food items are to ultimately end up in the nest, why would the ants temporarily discard them? 

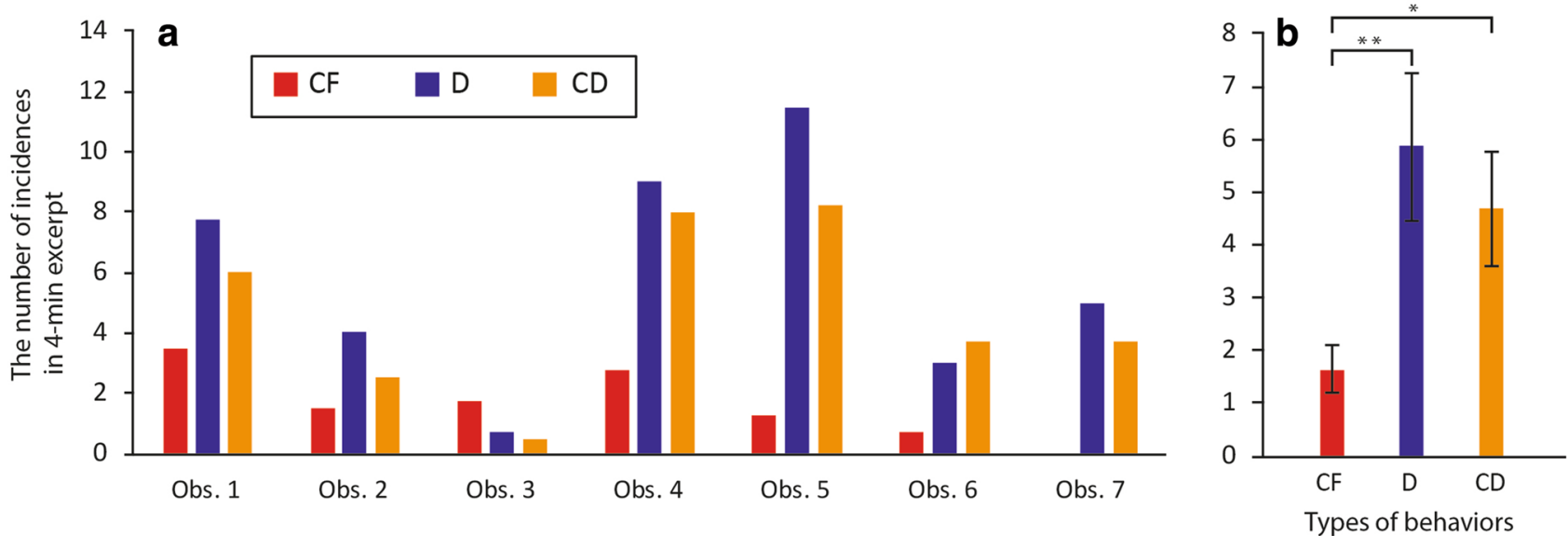

Fig. 2a, b The occurrence of the three types of behavior during the analyzed 4 min of video clips. a The number of incidences of three categorical behaviors from seven observation sessions. Observations (Obs.) 1-4 The provided food pile was located on the lower floor (as in Site A, Fig. 1b). Observations (Obs.) 5-7 Otherwise, the provided food pile was located on the right side of the nest, on the planter curb (as in Site B, Fig. 1b). CF Carrying tuna bits from the fresh tuna pile

The regulation of the protein content of a nest is essential for colony survival, so some ants expel protein according to the colony condition (Kay et al. 2010; Dussutour and Simpson 2009, 2012). We speculate that individual ants might have temporarily lacked communication with other ants, or each ant might have used different criteria for food quality assessment. Ants in a colony need to coordinate their decisions, and they can achieve this in various ways (Robinson et al. 2009). While social hegemony often outweighs the decisions made by an individual ant (Josens et al. 2016), some species of ants exhibit personality or cognitive state differences among individuals, which affect the collective decision-making process (d'Ettorre et al. 2017). It has been indicated that decision-making regarding nest selection depends on positive feedback for convergence on a unanimous decision (Mallon et al. 2001). Considering the above, although there is discordance regards food acceptance, whether from lack of communication or from individual difference, this could be resolved by continual compliance with the decision made by the majority.

Alternatively, the ants might have been temporarily caching or hoarding the tuna bits, using the dump as a means of temporary storage, as many of the tuna bits stayed on the putative dump site for a limited period of time. Another compatible explanation is that the dump area was treated as a functional part of the nest, in which ants could store and redistribute food items (Markin 1970; Reyes-López and Fernández-Haeger 2002).

The distances from the colony where we observed this phenomenon to the two other colonies that were studied were $80 \mathrm{~m}$ and $145 \mathrm{~m}$, but no similar behaviors were to the nest, $D$ discarding tuna bits from the nest, $C D$ carrying the discarded tuna bits back to the nest. b The average number of incidences of each behavior. Error bars represent SEM. During the analysis intervals, ants generally discarded food items more often than bringing items from the food pile. On the other hand, the intensity of food discarding $(D)$ and that of total food brought to the nest $(C F+C D)$ were not significantly different

observed in these nests, suggesting that the studied behavior is a colony-specific phenomenon. To our knowledge, this is the first report on the incongruity of food acceptance among the workers of $C$. japonicus. Further studies should focus on the frequency of occurrence and underlying mechanisms of this behavior.

Acknowledgments This research was supported by the Big Data Institute of Seoul National University and the BK21 Program, with the additional contribution of grant NRF 2016R1D1A1B03934340.

Open Access This article is distributed under the terms of the Creative Commons Attribution 4.0 International License (http://creativeco mmons.org/licenses/by/4.0/), which permits unrestricted use, distribution, and reproduction in any medium, provided you give appropriate credit to the original author(s) and the source, provide a link to the Creative Commons license, and indicate if changes were made.

\section{References}

Ballari S, Farji-Brener AG, Tadey M (2007) Waste management in the leaf-cutting ant Acromyrmex lobicornis: division of labour, aggressive behaviour, and location of external refuse dumps. $\mathbf{J}$ Insect Behav 20(1):87-98

Cook SC, Behmer ST (2010) Macronutrient regulation in the tropical terrestrial ant Ectatomma ruidum (Formicidae): a field study in Costa Rica. Biotropica 42(2):135-139

d'Ettorre P, Carere C, Demora L, Le Quinquis P, Signorotti L, Bovet D (2017) Individual differences in exploratory activity relate to cognitive judgement bias in carpenter ants. Behav Proc 134:63-69

Dussutour A, Simpson SJ (2009) Communal nutrition in ants. Curr Biol 19(9):740-744 
Dussutour A, Simpson SJ (2012) Ant workers die young and colonies collapse when fed a high-protein diet. Proc R Soc B Biol Sci 279(1737):2402-2408

Garnier S, Gautrais J, Theraulaz G (2007) The biological principles of swarm intelligence. Swarm Intell 1(1):3-31

Hart AG, Ratnieks FL (2002) Waste management in the leaf-cutting ant Atta colombica. Behav Ecol 13(2):224-231

Hölldobler B, Wilson EO (1990) The ants. Harvard University Press, USA

Josens R, Mattiacci A, Lois-Milevicich J, Giacometti A (2016) Food information acquired socially overrides individual food assessment in ants. Behav Ecol Sociobiol 70(12):2127-2138

Kay AD, Zumbusch T, Heinen JL, Marsh TC, Holway DA (2010) Nutrition and interference competition have interactive effects on the behavior and performance of Argentine ants. Ecology 91(1):57-64

Lenth RV (2016) Least-squares means: the R package lsmeans. J Stat Softw 69(1):1-33

Mallon E, Pratt S, Franks N (2001) Individual and collective decisionmaking during nest site selection by the ant Leptothorax albipennis. Behav Ecol Sociobiol 50(4):352-359
Markin GP (1970) Food distribution within laboratory colonies of the argentine ant, Tridomyrmex humilis (Mayr). Insect Soc 17(2):127-157

Pinheiro J, Bates D, DebRoy S, Sarkar D, Team RC (2007) Linear and nonlinear mixed effects models. R package version 3(57):1-89

Reyes-López JL, Fernández-Haeger J (2002) Food storage in the nest and seed selectivity in the harvester ant Messor barbarus. Sociobiology 39(1):1-6

Robinson EJ, Smith FD, Sullivan KM, Franks NR (2009) Do ants make direct comparisons? Proc R Soc Lond B Biol Sci 276(1667):2635-2641

Publisher's Note Springer Nature remains neutral with regard to jurisdictional claims in published maps and institutional affiliations. 